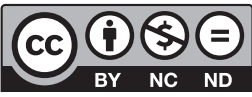

Estudos Teológicos foi licenciado com uma Licença Creative Commons Atribuição - NãoComercial - SemDerivados 3.0 Não Adaptada

http://dx.doi.org/10.22351/et.v59i1.3658

\title{
ViolêNCIA LETAL, A FALTA DE RESSONÂNCIA E O DESAFIO DO PERDÃo NO BRASIL ${ }^{1}$
}

\author{
Lethal violence, the lack of resonance \\ and the challenge of forgiveness in Brazil
}

\section{Rudolf von Sinner ${ }^{2}$ Euler Renato Westphal ${ }^{3}$}

\begin{abstract}
Resumo: Conforme levantamentos recentes, temos no Brasil um crescimento de violência letal, bem como indícios de uma brutalidade crescente dos crimes. Tais dados apontam para a existência de uma ampla percepção da impunidade e de uma aparente naturalidade do ato de matar. Autojustiça, linchamentos, desprezo a reais e supostos infratores, a busca de vingança e do exercício de poder sobre outros encontram, assim parece, suporte num tipo de justiça retributiva num ambiente onde as relações entre pessoas são regidas por uma plausibilidade de violência que impede a ressonância e o sentimento de autoeficácia. O objetivo deste ensaio é analisar a situação no Brasil, recorrendo a aclamados intérpretes como o historiador Sérgio Buarque de Holanda, ponderando razões da violência recorrendo à teoria da ressonância de Hartmut Rosa, bem como refletir sobre uma teologia da justiça que, antes de promover vingança, enfatize transformação, perdão e reconciliação, retomando reflexões de Hannah Arendt. Referindo-se a Jürgen Moltmann, o artigo procura mostrar como uma teologia pública pode contribuir para tal transformação.
\end{abstract}

Palavras-chave: Violência. Justiça. Perdão. Teoria da ressonância.

1 O artigo foi recebido em 26 de abril de 2019 e aprovado em 30 de maio de 2019 com base nas avaliações dos pareceristas ad hoc.

Uma versão anterior deste texto foi publicada como SINNER, Rudolf von; WESTPHAL, Euler Renato. Lethal Violence, the Lack of Resonance and the Challenge of Forgiveness in Brasil. International Journal of Public Theology, Leiden, v. 12, n. 1, p. 38-55, 2018. O texto foi traduzido por Luis Marcos Sander com apoio do PROEX/CAPES, revisado, abreviado e atualizado pelos autores.

2 Doutor e livre-docente em Teologia. Professor adjunto de Teologia Sistemática no Programa de Pós-Graduação em Teologia da Pontifícia Universidade Católica do Paraná (PUCPR); de 2003-2019 professor titular de Teologia Sistemática, Ecumenismo e Diálogo Inter-religioso na Faculdades EST em São Leopoldo/ RS. Bolsista de Produtividade em Pesquisa do CNPq. Contato: rudolf.sinner@pucpr.br

3 Doutor em Teologia. Professor de Teologia Sistemática na Faculdade Luterana de Teologia (FLT) em São Bento do Sul/SC e no Programa de Pós-Graduação em Patrimônio Cultural e Sociedade na Universidade de Joinville/SC (Univille). Contato: eulerwestphal@gmail.com 
Abstract: According to recent data there has been a considerable increase in lethal violence in Brazil as well as evidence of a growing brutality. Such data bears witness to the wide perception of impunity and the apparent commonality of killing. Self-justice, lynchings, contempt of real or supposed delinquents, the search for revenge and the exercise of power over others find support, so it seems, in a kind of retributive justice within an environment in which relationships between persons are driven by a plausibility of violence that inhibits resonance and the sentiment of self-efficacy. The purpose of this essay is to analyse the situation in Brazil, referring to acclaimed interpreters as historian Sérgio Buarque de Holanda, to ponder possible reasons for violence using the sociological theory of resonance by Hartmut Rosa, and to reflect on a theology of justice that, rather than revenge, emphasises transformation, forgiveness and reconciliation, taking up reflections by Hannah Arendt. Through reference to Jürgen Moltmann, it seeks to show how a public theology can contribute to such transformation.

Keywords: Violence. Justice. Forgiveness. Theory of resonance.

\section{Introdução}

Em anos recentes, houve um crescimento significativo em violência letal no Brasil, tanto em termos numéricos como no grau de brutalidade. Tal fenômeno de violência é complexo. É difícil compreender e lidar com ele porque implica muitos atores e fatores. Atinge vítimas, infratores e infratoras, funcionárias e funcionários do sistema de segurança pública, e, também, convicções culturais e religiosas profundamente arraigadas na sociedade. O relatório das Nações Unidas sobre violência e saúde define violência como "uso intencional da força física ou do poder, real ou em ameaça, contra si próprio, contra outra pessoa, ou contra um grupo ou uma comunidade, que resulte ou tenha grande possibilidade de resultar em lesão, morte, dano psicológico, deficiência de desenvolvimento ou privação"4. Nosso ponto de partida neste artigo é a violência interpessoal, física e letal. Nosso interesse está voltado ao clima mais amplo favorável à legitimação da violência e sua "naturalidade" na percepção pública. Tal clima fomenta atitudes frente a infratores ou infratoras, bem como outras pessoas com determinadas características, que chegam a ser vistas como "merecendo" violência.

Em ambos os casos, o que está em pauta é o reconhecimento - ou a negação desse - de sua dignidade humana. De acordo com o preâmbulo da Declaração Universal de Direitos Humanos (1948), “o reconhecimento da dignidade inerente a todos os membros da família humana e dos seus direitos iguais e inalienáveis constitui o fundamento da liberdade, da justiça e da paz no mundo". Entre os direitos assegurados a todos os seres humanos estão, conforme o artigo $3^{\circ}$ da mesma Declaração, o "direito

4 WHO Global Consultation on Violence and Health. Violence: a public health priority (1996), apud KRUG, Etienne G. et al. (Eds.). Relatório Mundial sobre violência e saúde. Genebra: Organização Mundial da Saúde, 2002. p. 5. Disponível em: <https://www.opas.org.br/wp-content/uploads/2015/09/relatoriomundial-violencia-saude.pdf $>$. Acesso em: 23 mar. 2019. 
à vida, à liberdade e à segurança pessoal"'s . A integridade física de uma pessoa, sua vida, liberdade e segurança são centrais para os direitos humanos e, teologicamente, estão fundamentadas na criação de todas as pessoas à imagem e semelhança de Deus (Gênesis 1.27-28), de forma igualitária, sem distinção de qualquer natureza, o que lhe confere sua dignidade. A partir do imago Dei, “a vida é bem supremo. E, embora esse pressuposto seja certamente de origem cristã, não passa de circunstância importante presente à fé cristã" . Observa-se, assim, uma relação intrínseca entre o conceito da dignidade humana da tradição teológica judaico-cristã do imago Dei e a Declaração dos Direitos Humanos da ONU. ${ }^{7}$ Tendo em vista as inúmeras violações de tal integridade, inclusive por e de pessoas cristãs, quais contribuições uma teologia cristã que se entende como pública ${ }^{8}$ pode oferecer para e fomentar perdão e reconciliação? Ainda que de forma incipiente e um tanto intuitiva, defendemos que tal contribuição passa por uma compreensão alternativa de justiça, vista como transformadora e não vingativa.

Uma primeira seção é dedicada à experiência diária da violência letal no Brasil, descrevendo alguns eventos concretos e dando uma resposta inicial à questão pelas razões do alto número de assassinatos e sua aparente plausibilidade no discurso geral. A segunda seção aborda elementos de uma possível matriz cultural da violência. Procuramos compreender melhor a aparente naturalidade do ato de matar a partir do pensamento de reconhecidos - embora também debatidos - intérpretes do Brasil, especialmente de Sérgio Buarque de Holanda. Em seguida, em referência ao sociólogo alemão Hartmut Rosa, quem recentemente publicou uma notável teoria da ressonância como forma de relacionamento com o mundo, procuramos compreender os atos de violência descritos como possível reação a uma falta de ressonância sofrida pelos infratores. Nessa visão, a violência é uma forma de exercício de poder e superação da vulnerabilidade própria por meio da exposição e do abuso da vulnerabilidade de outras pessoas, assim configurando-se como forma de compensação pela falta de ressonância por meio de atos de negação da mesma a outras pessoas. A terceira seção discutirá conceitos de justiça, especialmente a partir de abordagens de Jürgen Moltmann, nas quais, entre outros, elementos teológicos inovadores e atitudes promovidas por igrejas são vistos como necessários para promover uma justiça transformadora em vez de uma justiça retributiva e vingativa. Na quarta seção procuraremos apresentar aspectos de perdão e reconciliação a partir da interpretação proposta por Hannah Arendt sobre a prática e a mensagem de Jesus.

5 ORGANIZAÇÃO DAS NAÇÕES UNIDAS. Declaração Universal dos Direitos Humanos (1948). Disponível em: <https://www.ohchr.org/EN/UDHR/Documents/UDHR_Translations/por.pdf>. Acesso em: 23 mar. 2019.

6 ARENDT, Hannah. Condição humana. 10. ed. Trad. Roberto Raposo. Rio de Janeiro: Forense Universitária, 2008. p. 332.

7 Cf. HABERMAS, Jürgen. Fé e Saber. In: O Futuro da Natureza Humana. São Paulo: Martins Fontes, 2004. p. 135-154; JOAS, Hans. A sacralidade da pessoa. Nova genealogia dos direitos humanos. São Paulo: UNESP, 2013.

8 Ver, p. ex., SINNER, Rudolf von. Teologia pública num estado laico. Ensaios e análises. São Leopoldo: Sinodal; EST, 2018. (Teologia pública v. 7). 


\section{A experiência diária de violência letal no Brasil}

Num sábado pela manhã, por volta das 11 horas, no Aeroporto Internacional Salgado Filho em Porto Alegre, Marlon Roldão Soares foi morto por 15 balas em pleno saguão do terminal de passageiros. Ele completara 18 anos naquele dia. Aparentemente, ele se envolvera com o tráfico de drogas e foi executado em função da noção de justiça do tráfico. Ato horrífico já como tal, ele constitui apenas a ponta de um iceberg: tirar a vida de alguém parece ser algo cada vez mais normal e bastante seguro de executar, mesmo no meio de um local altamente vigiado e protegido como é um aeroporto. De acordo com dados do UNODOC, o Escritório das Nações Unidas sobre Drogas e Crime, somente no estado do Rio Grande do Sul o índice de homicídios é de 25,2 por 100 mil habitantes, enquanto que em âmbito mundial é 6,2. As Américas como um todo apresentam um já muito alto índice de 16,3. ${ }^{9}$ Segundo o Atlas da Violência 2018, o Brasil alcançou, em 2016, o maior número já registrado, de 62.517 homicídios, chegando a um índice de 30,5 por 100 mil habitantes. Na população entre 15 e 19 anos, o índice sobe para 142,7, sendo o homicídio a maior causa de óbito entre homens nessa faixa etária, respondendo por 56,5\% das mortes. A maior parte dos homicídios, $71,1 \%$, é cometida por arma de fogo. ${ }^{10}$ Atinge principalmente homens jovens e negros com pouca escolaridade. ${ }^{11}$ Ainda que as vítimas (e os infratores) sejam predominantemente do sexo masculino, a taxa de feminicídio também é alta, em 4,8 por 100 mil mulheres. De acordo com a Organização Mundial de Saúde (OMS), esse é o quinto número mais alto no mundo. ${ }^{12}$ As evidências também mostram que os assassinos estão cada vez mais desinibidos no tocante à brutalidade de seus atos. ${ }^{13}$

Diante desse quadro, surge a pergunta pelas razões dessa violência, que parece indicar tão alto grau de banalização da vida. Há claramente fatores concretos que fomentam ou, no mínimo, não inibem o crime. ${ }^{14}$ Também há convicções profundamente

9 UNITED NATIONS OFFICE ON DRUGS AND CRIME. Global Study on Homicide 2013: Trends, Contexts, Data. Vienna: UNODC, 2013, 22.24.

${ }^{10}$ CERQUEIRA, Daniel et al. Atlas da Violência 2018. Rio de Janeiro: IPEA; Fórum Brasileiro de Segurança Pública, 2018. p. 3-5.

${ }^{11}$ Ver CERQUEIRA et al., 2018; WAISELFISZ, Júlio Jácobo. Mortes Matadas por Armas de Fogo. Mapa da Violência 2015. Brasília: Secretaria Geral da Presidência da República et al., 2015.

${ }^{12}$ ORGANIZAÇÃO DAS NAÇÕES UNIDAS. ONU: Taxa de feminicídios no Brasil é quinta maior do mundo: diretrizes nacionais buscam solução. Publicado em 09 abr. 2016 e editado em 12 abr. 2016. Disponível em: $<$ https://nacoesunidas.org/onu-feminicidio-brasil-quinto-maior-mundo-diretrizesnacionais-buscam-solucao/>. Acesso em: 23 abr. 2019.

${ }^{13}$ CARIELLO, Gabriel; FALDO, Rafael. Exibidas em vídeos, decapitações viram demonstração de força de grupos criminosos. O Globo on-line de 06 de janeiro de 2017, 04:30h, atualizado em 08:36h. Disponível em: <https://oglobo.globo.com/brasil/exibidas-em-videos-decapitacoes-viram-demonstracao-de-forcade-grupos-criminosos-20735442>. Acesso em: 23 abr. 2019.

${ }^{14}$ Ver, por exemplo, o relatório de pesquisa empírica com recomendações, viradas principalmente para a atuação do Estado, de CHESNAIS, Jean-Claude. Violência no Brasil. Causas e recomendações políticas para sua prevenção. Ciência e Saúde Coletiva, v. 4, n. 1, p. 53-69, 1999; mais amplo e interdisciplinar é ALMEIDA, Maria da Graça Blaya (Org.). A Violência na Sociedade Contemporânea. Porto Alegre: EDIPUCRS, 2010. Disponível em: <http://ebooks.pucrs.br/edipucrs/violencia.pdf>. Acesso em: 23 maio 2019. 
arraigadas que geram um clima de legitimidade da violência. Um criminoso em potencial ou real não é considerado apenas um perigo para a sociedade, mas alguém que perdeu seu direito à existência. Logo, ele não tem mais direito à dignidade humana e a um tratamento correspondente a ela. A morte de um criminoso, mesmo que não tenha sido condenado, mas apenas seja percebido como tal, parece ser legítima. Metade da população acha que "bandido bom é bandido morto"" . Há crime real, mas também existe um "discurso do crime" que reforça diariamente a ideia de que, dentro dos muros, o mundo é bom, e fora deles, é mau e perigoso. ${ }^{16}$ Antes de analisar tal legitimidade baseada em noções questionáveis de justiça, apresentamos a violência como possível consequência da falta de ressonância.

\section{A violência como consequência da falta de ressonância}

O autor austríaco Stephan Zweig (1881-1942) considerava o Brasil o "país do futuro". Sua condição de judeu que teve que fugir da Alemanha nazista no início da década de 1940 informou tal percepção. Zweig maravilhou-se com o que percebeu como um convívio harmonioso de três traças: a europeia, a africana e a indígena. Isso combinava bem com o nacionalismo brasileiro, que estava se formando na época sob o governo ditatorial de Getúlio Vargas. Ao mesmo tempo, contudo, tratava-se de uma redução romântica da realidade. É, certamente, reducionista afirmar o que Zweig disse:

Tudo o que é brutal repugna ao brasileiro, e está verificado por estatística que o assassínio aqui quase nunca é praticado com premeditação, é quase sempre espontâneo, é um crime passional, é o resultado de uma explosão súbita de ciúme ou do sentimento de haver sido ofendido. [...] Quando um brasileiro puxa da faca, está, por assim dizer, num estado de exaltação nervosa [...] Mas em geral - e isto é confirmado por todo imigrado - ao brasileiro é alheio tudo o que é violência, brutalidade e sadismo, mesmo nos mais imperceptíveis traços. O brasileiro é de boa índole e de boa fé $[\ldots]^{17}$.

Zweig não percebeu que a violência presente na estrutura de um sistema escravocrata de longa duração moldou a sociedade brasileira desde a casa grande até a senzala, para usar a expressão de Gilberto Freyre ${ }^{18}$, e deixou suas marcas, mesmo que nem sempre muito visíveis. Há uma contradição evidente entre a harmonia e a cordia-

15 PAGNAN, Rogério. Metade do país acha que "bandido bom é bandido morto", aponta pesquisa. Folha de S. Paulo on-line, 05 out. 2015, 02h00. Disponível em: <http:/www1.folha.uol.com.br/ cotidiano/2015/10/1690176-metade-do-pais-acha-que-bandido-bom-e-bandido-morto-aponta-pesquisa. shtml>. Acesso em: 23 abr. 2019.

${ }^{16}$ CALDEIRA, Teresa P. R. Cidade de muros. Crime, segregação e cidadania em São Paulo. 2. ed. São Paulo: Ed. 34; EDUSP, 2003. Disponível em: < https://csociais.files.wordpress.com/2014/05/caldeira-teresa-acidade-de-muros-completo.pdf>. Acesso em: 23 abr. 2019.

17 ZWEIG, Stefan. Brasil, país do futuro. Trad. Odilon Galotti. Edição eletrônica de Ridendo Castigat Mores. Versão para e-book. eBooksBrasil. p. 204. Disponível em: < http://www.ebooksbrasil.org/adobeebook/ paisdofuturo.pdf>. Acesso em: 23 abr. 2019.

18 FREYRE, Gilberto. Casa Grande e Senzala: formação da família brasileira sob o regime da economia patriarcal. 28. ed. Rio de Janeiro: Record, 1992. (Introdução à história da sociedade patriarcal no Brasil, 1). 
lidade das diferentes populações que vivem no Brasil, como afirmou existir Zweig, e a violência letal cada vez mais comum.

O que dizer, então, da "cordialidade" dos brasileiros descrita pelo historiador Sérgio Buarque de Holanda (1902-1982) em seu Raizes do Brasil? ${ }^{19}$ Percebida como característica cultural comum da população brasileira, a cordialidade é a relação de troca de favores, recompensas e benefícios com a intenção de ganhar alguma vantagem para si mesmo, seus amigos ou sua família. É uma forma de construção de relações baseada em emoções. Pode possuir grande qualidade e aparentar uma virtude, mas também pode nutrir ressentimento, ódio e violência. Para Holanda, "o humano cordial" - caracterizando um tipo ideal sociopsicológico e uma forma de relacionar-se com outras pessoas ${ }^{20}$ - não se refere tanto a ser gentil, mas a ser governado pelo coração, por um "ethos da emoção" ${ }^{21}$ Ele se expressa em relações altamente personalizadas, afetuosas e emocionais antes de em princípios universais abstratos. Esse tipo de cordialidade pode aparecer como manifestações de orgulho pelo país e de amor pelos amigos, pela família, pelo time preferido (o time do coração), mas podem, no minuto seguinte, transformar-se em violência, ódio e desprezo contra o inimigo e, em alguns casos, inclusive contra o amigo. A emoção prevalece sobre a razão e princípios abstratos de qualquer espécie. O antropólogo Roberto DaMatta afirma isto consistentemente em seu Carnavais, malandros e heróis, que as relações pessoais, afetivas, mesmo que assimétricas, triunfam sobre a lei abstrata que visa proteger cada indivíduo de forma igual. ${ }^{22}$ De fato, o indivíduo é uma pessoa solitária e marginalizada porque a vida em sociedade se baseia em relacionamentos, muitas vezes em torno de um patrão poderoso que manda e exige, mas também cuida e recompensa. Ironicamente, apesar de todo o discurso sobre a importância da cidadania ${ }^{23}$, as pessoas que comumente são chamadas de "cidadão" nas ruas são as que ninguém conhece e com as quais jamais se teve alguma relação.

Assim, a despeito de toda a gentileza, generosidade e cordialidade - o que, certamente, é uma realidade em muitos casos -, há brutalidade, há violência. Como

19 HOLANDA, Sérgio Buarque de. Raízes do Brasil. 27. ed. São Paulo, SP: Companhia das Letras, 2015. Para uma análise bem ponderada da tese de Holanda ver COSTA, Sérgio. O Brasil de Sérgio Buarque de Holanda. Revista Sociedade e Estado, v. 29, n. 3, p. 823-839, 2014. Costa enxerga o perigo de um essencialismo na recepção do conceito de cordialidade e enfatiza tratar-se de um elemento de todas as relações interpessoais. Já SOUZA, Jessé. A Elite do Atraso. São Paulo: Leyva, 2017, nesta e em várias outras obras, faz uma crítica contundente de Holanda, afirmando que esse não teria levado em conta o fato da escravidão e da hierarquia (e brutalidade) das relações por ela estabelecidas. Enquanto essa crítica precisa ser levada em conta e aponta um fator importante, nos parece que as raízes como indicadas na obra de Holanda configuram um elemento da humanidade que se concretiza de forma específica - embora não única nem exclusiva - no contexto brasileiro e tem uma influência sobre a violência.

${ }^{20}$ COSTA, 2014, p. 824.

${ }^{21}$ HOLANDA, 2015, p. 119.

22 DAMATTA, Roberto. Carnavais, malandros e heróis. Para uma sociologia do dilema brasileiro. 6. ed. Rio de Janeiro: Rocco, 1997.

23 Ver SINNER, Rudolf von. Cidadania no Brasil: Teoria, prática, teologia. In: BUTTELLI, Felipe Gustavo; LE BRUYNS, Clint; SINNER, Rudolf von (Orgs.). Teologia pública no Brasil e na África do Sul: cidadania, interculturalidade e HIV/AIDS. São Leopoldo: Sinodal, EST, 2014. p. 13-46. (Teologia pública v. 4). 
uma das razões que gera essas atitudes e atos pode ser considerada a falta de ressonância. As pessoas que não experimentam ressonância anestesiam suas atitudes para com outras pessoas e não têm sentimento algum pela vítima, ou então se comprazem em exercer poder sobre ela e, assim, justamente não estabelecem uma relação de ressonância mútua. Tentaremos explicar isso a seguir.

O sociólogo alemão Hartmut Rosa publicou recentemente um extenso livro sobre a ressonância como forma de relação com o mundo. A ressonância é o que cria relações entre pessoas assim como com objetos e com Deus. Não se trata de um mero eco, um refletir de sons, mas, antes, uma resposta autêntica de alguém às vibrações que alguém outro está emitindo. "A ressonância ocorre [...] quando, pela vibração de um corpo, a própria frequência de outra pessoa é estimulada." ${ }^{24}$ Isso acontece em um espaço que permite que tal ressonância ocorra, mas não a faz acontecer forçosamente. $\mathrm{Na}$ teoria de Rosa, a ressonância é uma realidade emocional, neurológica e corporal, um elemento básico da existência social e cultural. Para ele, a ressonância se torna o metacritério para a vida bem-sucedida, cuja qualidade não pode ser medida meramente pelo acesso à riqueza, opções ou recursos materiais, mas também pela qualidade da relação com o mundo. O oposto da ressonância é a alienação. Quando a ressonância é negada, as pessoas adoecem e podem morrer. Se as pessoas não vivenciam a eficácia delas próprias (Selbstwirksamkeit) no que fazem, porque não têm o poder de influenciar o mundo de uma forma que produza ressonância, elas ficam frustradas. É, portanto, crucial que as pessoas destituídas de poder cheguem a sentir a própria eficácia. Poderíamos dizer que infligir violência a outras pessoas produz eficácia própria, mas à força e, por conseguinte, não gera ressonância nem estabelece uma relação caracterizada por ressonância - pelo contrário, diz Rosa: "É certo que por meio da repressão e violência a ressonância pode ser impedida, produzindo-se a alienação repulsiva" ${ }^{25}$. De fato, o infrator violento tenta compensar sua própria experiência de repulsa. No entanto, ele é incapaz de produzir uma relação de ressonância: "Sua relação com o mundo permanece repulsiva, a repulsa é tão somente revertida em sua polaridade. Ela não mais emana do mundo, mas do sujeito. $\mathrm{O}$ infrator antecipa, agora, o mundo hostil”26.

Se isso for correto, a falta de ressonância na família e na sociedade e a consequente falta de eficácia própria criam uma sensação de impotência que pode ser momentaneamente compensada pela participação em um grupo criminoso e sua lealdade - embora essa seja sempre precária -, bem como pela obtenção de respeito através do medo imposto a outras pessoas pelo poder das armas. Se uma sociedade toda transmite a ideia de que algumas pessoas têm direito a viver e a viver bem, enquanto outras não, que algumas têm direito à existência, enquanto outras não, por que a vida em geral deveria ser algo a ser protegido? Holanda mostrou como, desde a época colonial, a resolução de conflitos por meio do homicídio tem tido ampla plausibilidade, seja

${ }^{24}$ ROSA, Hartmut. Resonanz: Eine Soziologie der Weltbeziehung. Berlin: Suhrkamp, 2016. p. 282.

${ }^{25}$ ROSA, 2016, p. 757.

${ }^{26}$ Tradução do tradutor do artigo. No original: "Seine Weltbeziehung bleibt repulsiv, die Repulsion wird lediglich umgepolt, sie geht jetzt nicht mehr von der Welt, sondern vom Subjekt aus. Der Täter kommt der feindseligen Welt nun zuvor“. ROSA, 2016, p. 745. 
como ato para restabelecer a honra, como ato de dominação ou como ato de resistência. Todos esses podem ser vistos como atos que negam a relação, a ressonância, a busca de soluções que não a aniquilação do outro. Isso é corroborado pelo psicanalista Jurandir Freire Costa, quando afirma:

\begin{abstract}
Na delinquência urbana, de forma análoga [sc. análoga à situação da guerra contra o Iraque], para matar não são necessários maiores pretextos. Se a arma está engatilhada e o ímpeto diz sim, ai de quem está à mão! Mata-se a avó por dinheiro para comprar cocaína; uma adolescente de 14 anos morre, porque alguém quis roubar qualquer coisa no metrô e enfrentou o tiroteio da polícia; mata-se um professor universitário porque não deveria estar ali, na hora do assalto; matam-se policiais porque são "policiais", e bandidos porque são "bandidos". Enfim, mata-se, mata-se e mata-se. E o mais duro é que, se perguntarmos qual a verdadeira razão de tantas mortes, a resposta vem nua e crua: mata-se para manter vivo um estilo de vida nefasto e em vias de extinção. As matanças em massa que assistimos exprimem a fúria de um mundo agonizante. Essa monstruosidade social definha e, nos últimos estertores, devora corpos e esperanças, em uma espécie de canibalismo genocida que parece saído das histórias de ficção científica ${ }^{27}$.
\end{abstract}

Os espantosos níveis de violência letal testemunham a extensão na qual é vista e praticada como uma "solução" de conflito plausível e comum. Tornou-se endêmica. A razão de ser dessa situação está muito além da emocionalidade e reação passional. A frieza e a "naturalidade" com que atos de violência podem ser vistos e executados parecem ser sustentadas por determinada compreensão e prática de justiça, uma justiça que procura vingança antes de transformação e reconciliação. Há mais de um século, o autor baiano Jorge Amado, referindo-se a uma situação particular ao redor da virada do século (1900), observou que a ordem de execução dada por um patrão tinha que ser executada sem ser questionada. Pouco mudou desde então: a morte encomendada como justa e encarada com profissionalismo. ${ }^{28}$ Uma justiça vingativa que alimenta a espiral da violência. Não permite perdão e reconciliação com o fim de restabelecer relações e continuar a convivência. Sobre isso refletimos na próxima seção.

\title{
Violência, justiça e perdão
}

Não é difícil evidenciar que justiça no Brasil se configura, principalmente, como retributiva. A intenção tácita é de restabelecer a honra, exercer domínio e punição ou vingança. $\mathrm{O}$ critério da balança da justiça tem o seguinte princípio: se o peso da maldade for maior em um dos pratos da balança, a vida estará perdida. A lei aplicada pelo tráfico de drogas tem regras muito claras e não há perdão. Tal prática pode ser

${ }^{27}$ COSTA, Jurandir Freire. A fúria de um mundo agonizante. Folha de S. Paulo, Caderno Mundo, p. A22, 01 abr. 2003. Disponível em: <http://www1.folha.uol.com.br/folha/mundo/ult94u54275.shtml >. Acesso em: 23 dez. 2016.

28 AMADO, Jorge. Terras do sem fim. São Paulo: Companhia das Letras, 2008. Estudantes nossos, especialmente das regiões Norte e Nordeste, confirmam a contínua existência daquelas pessoas que fazem "o serviço", matando por pagamento. 
vista como forma precária de manutenção da ordem e fornecimento de orientação no mundo. Favelas sob o poder de gangues do tráfico no Rio de Janeiro muitas vezes funcionam de uma maneira mais ordenada e tranquila do que quando sob o poder da polícia. Tem sua própria eficácia, ainda que a um preço muito alto. ${ }^{29}$

$\mathrm{O}$ mesmo princípio se aplica na sociedade mais ampla. A prática comum e o senso comum exigem que essa justiça retributiva seja executada e aplicada imediatamente. $\mathrm{O}$ seguinte pensamento encontra chão fértil: "Se a polícia não consegue resolver o problema, então temos que fazê-lo nós mesmos" - e, assim, a prática do linchamento tem se tornado algo bastante comum, mas pouco comentado. ${ }^{30} \mathrm{O}$ mau funcionamento do sistema judiciário e as falhas da polícia em manter a segurança e realizar investigações com sucesso reforçam a sensação de abandono e promovem ainda mais a busca de uma "solução" rápida e definitiva.

Ao mesmo tempo constatamos que a grande maioria dos brasileiros se declara cristã. Essa confissão poderia produzir outra perspectiva e maior ênfase em variações da justiça restaurativa e o fortalecimento de linhas de relacionalidade dentro de uma sociedade civil. No entanto, as próprias igrejas muitas vezes promovem opiniões e soluções que são propícias a abonar ações violentas. ${ }^{31}$ Embora certamente não defendam assassinatos, seu rigorismo moral tende a confirmar que a balança da justiça deve apontar para a retribuição.

Diante da predominância de noções retributivas de justiça que parecem dar sustento a um clima favorável à violência, o desafio teológico consiste em redescobrir e promover uma noção diferente de justiça, propícia a reduzir a violência. Jürgen Moltmann defende uma justiça transformadora que se dirija para o futuro, não para a medição do passado. Ele afirma que "assim, devemos imaginar também o juízo final como um julgamento da paz pela vida e não como julgamento de castigo que decide sobre a vida e a morte" ${ }^{32}$. Reconhece que a ideia do juízo final não é originalmente cristã nem bíblica: Israel recebeu e transformou, criativamente, conceitos de justiça do Egito e da Babilônia à luz de sua própria fé. O modelo "egípcio", baseado no Livro dos Mortos, é antropocêntrico. Em sua transição desta vida para o outro mundo, seres humanos têm seu coração e seus atos pesados um contra outro numa balança vigiada por Anubis antes de serem julgados por Osiris no "salão da verdade". De acordo com o princípio da Ma'at, de justiça e verdade, seres humanos recebem compensação por

${ }^{29}$ Cf. SILVA, Luiz Antonio Machado da; LEITE, Márcia Pereira. Violência, crime e polícia: o que os favelados dizem quando falam desses temas? Sociedade e Estado, v. 22, n. 3, p. 545-591, 2007.

${ }^{30}$ MARTINS, José de Souza. Linchamentos: a justiça popular no Brasil. São Paulo: Contexto, 2015.

${ }^{31}$ Cf. VILHENA, Valéria Cristina. Pela Voz das Mulheres: uma análise da violência doméstica entre mulheres evangélicas atendidas no Núcleo de Defesa e Convivência da Mulher - Casa Sofia. 2009. Dissertação (Mestrado) - Faculdade de Humanidades e Direito, Pós-Graduação em Ciências da Religião, Universidade Metodista de São Paulo, São Bernardo do Campo, 2009; KROB, Daniéli Busanello. Violência doméstica contra mulheres e ações de enfrentamento de igrejas: um estudo de caso. 2017. Tese (Doutorado) Faculdades EST, São Leopoldo, 2017.

32 MOLTMANN, Jürgen. Vida, esperança e justiça. Um testemunho teológico para a América Latina. São Bernardo do Campo: Editeo, 2008a. p. 129. 
seus atos com recompensa ou punição. ${ }^{33}$ Moltmann argumenta que a figura de Anubis teria inspirado, posteriormente, a figura do arcanjo Michael: Osiris, por sua vez, teria influenciado a ideia do Cristo como juiz. Já o modelo "babilônico" tem dois elementos que teriam sido incorporados a Israel: o sol como símbolo da ordem cósmica do mundo e da vida, e uma justiça cosmológica. Nos salmos, defende Moltmann, há uma "solarização" de Deus e o conceito cosmológico da justiça é traduzido para dentro de termos históricos numa perspectiva escatológica. "Se JHWH é adorado como 'sol da justiça' (Ml 3,20) e se faz uma oração para que este sol se levante, então o Deus de Israel também assume funções de dar vida, curar, salvar e de efetivar uma justiça corretiva do sol de Samas [o deus-sol babilônico]." ${ }^{34}$ Nessa última tradição, diz Moltmann, o juiz tem uma tarefa edificante, não punitiva: proteger os fracos e prover justiça para as pessoas às quais ela é negada. O grande juízo é, então, uma consequência da "injustiça que clama ao céu, de vítimas que não se calam e de assassinos que não encontram paz"35. As vítimas aguardam um julgamento não de acordo com obras, mas de acordo com seu sofrimento. O juízo final traz cura e justiça transformadora. Segundo o linguajar bíblico, Deus concede essa justiça com base em sua liberdade, não estando sujeito a uma lei externa, mas preferindo o amor a uma compreensão estreita de justiça retributiva. Antes e além da retribuição existem perdão, reconciliação e restauração. As vítimas são "erguidas" (aufgerichtet), e os autores de crimes são "corrigidos" (zurechtgebracht). A justiça deve estar voltada para o futuro, a serviço da nova criação, e não a serviço do pecado e da morte em um grande acerto de contas final. Trabalhar nessa profunda transformação do conceito de justiça e criar espaços para fomentar a ressonância é, em nossa opinião, uma tarefa central das igrejas e da teologia - não por último de uma teologia pública.

\section{Perdão e reconciliação: tarefas para uma teologia pública}

No contexto do crescimento de todos os tipos de violência no Brasil, uma das tarefas de uma teologia pública é refletir e propor processos que poderiam romper a espiral da violência. Se não fosse assim, estaria em vigor a lei do talião: "olho por olho, dente por dente" (Mateus 5.38). O perdão e a reconciliação são temáticas organizativas centrais para uma teologia pública em uma sociedade marcada por violência e vingança. Hannah Arendt aponta para as dimensões teológicas das dimensões políticas e sociais da culpa e do perdão. Para ela,

\footnotetext{
33 Ver ASSMANN, Jan. Tod und Jenseits im Alten Ägypten. 2. ed. München: Beck, 2010.

34 Tradução do tradutor do artigo. No original: „Wird JHWH als ,Sonne der Gerechtigkeit“ (Mal 3,20) gepriesen und um seinen Aufgang gebetet, dann übernimmt Israels Gott auch die Funktionen der lebendigmachenden, heilenden, rettenden und zurechtbringenden Gerechtigkeit der Sonne Samas". MOLTMANN, Jürgen. ,, Sein Name ist Gerechtigkeit“: Neue Beiträge zur christlichen Gotteslehre. Gütersloh: Gütersloher, 2008b. p. 118-136, à p. 119.

35 MOLTMANN, 2008b, p. 124.
} 
Descobridor do papel do perdão na esfera dos negócios humanos foi Jesus de Nazaré. O fato de que ele tenha feito esta descoberta num contexto religioso e a tenha enunciado em linguagem religiosa não é motivo para levá-la menos a sério num sentido estritamente secular ${ }^{36}$.

Seguindo a interpretação do apóstolo Paulo, a radicalidade do perdão de Jesus reside no fato de que ele foi feito o amaldiçoado de Deus e dos humanos. Cristo foi feito pecado por Deus. A confissão epistolar reza: Aquele que não conheceu pecado, ele o fez pecado por nós, para que, nele, fôssemos feitos justiça de Deus (2 Coríntios 5.21); e ainda: Cristo nos resgatou da maldição da lei, fazendo-se ele próprio maldição em nosso lugar - porque está escrito: "Maldito todo aquele que for pendurado em madeiro” (Gálatas 3.13). Lutero interpretou esse versículo afirmando que Cristo foi o amaldiçoado que tomou sobre si a maldição da humanidade. ${ }^{37}$ Como consequência da obra salvífica do Cristo, aqueles e aquelas que foram amaldiçoados e amaldiçoadas agora têm esperança para a transformação de suas vidas. Ele assumiu a maldição dos amaldiçoados e, por extensão, liberta as vítimas do desejo por vingança.

Hannah Arendt enxerga as implicações da nossa compreensão e prática de perdão: "Perdoar serve para desfazer os atos do passado, cujos 'pecados' pendem como espada de Dâmocles sobre cada nova geração"38. O perdão não é o único "remédio para desfazer o que foi feito" 39 e, assim, reparar o pecado irreversível. Arendt conclui: "A desobrigação mencionada nos ensinamentos de Jesus sobre o perdão é a libertação dos grilhões da vingança, uma vez que esta prende executor e vítima no inexorável automatismo do processo da ação que, por si, jamais chega necessariamente ao fim" "40. Assim, segundo ela, Jesus traz algo totalmente novo. O perdão existia em Roma como parcere subiectis, como poupar os derrotados da morte. Na Grécia, ele era desconhecido. Na tradição de Jesus, diz Arendt, o ato de perdoar pessoas também levava ao perdão de Deus (cf. Lc 5.21-24; Mt 18.35; Lc 17.3-4). Crimes e atos deliberados serão julgados no juízo final, na dimensão da escatologia final. O perdão em sua relação com a justiça é a dimensão de uma escatologia consumada. É ato unicamente de Deus.

O perdão é que é apropriado à condição humana e é o que deveria acontecer diariamente em nossas relações mútuas. Nessas relações, necessitamos do perdão recíproco que nos liberta dos grilhões da culpa para que uma vida autêntica seja possível. Viver na visão de um futuro é possível tão somente na medida em que o culpado é libertado de sua culpa e a vítima renuncia à vingança por meio de um ato de perdão. O perdão rompe o círculo vicioso da vingança. O perdão contém a surpresa do novo e não se deixa predeterminar pela ação do mal - e a consequente ausência de ressonância e autoeficácia. O perdão "liberta tanto o que perdoa quanto o que é perdoado". Não

\footnotetext{
36 ARENDT, 2008, p. 250.

37 Cf. LUTHER, Martin. Kommentar zum Galaterbrief [1519]. München: Siebenstern Taschenbuch, 1968. p. $135-140$.

38 ARENDT, 2008, p. 249.

39 ARENDT, 2008, p. 250.

40 ARENDT, 2008, p. 253.
} 
há mais necessidade de vingança. ${ }^{41}$ Aquele que ama está pronto para perdoar. A pessoa perdoada é amada com suas qualidades bem como com suas debilidades e transgressões. Essa incondicionalidade do perdão que inclui as peculiaridades do outro provém da palavra de Jesus que Hannah Arendt traduz desta maneira: "Se ele pecar sete vezes no dia contra ti, e sete vezes no dia te vier buscar dizendo: Pesa-me, perdoa-lhe" (cf. Lc 17.4). ${ }^{42}$ Desta maneira, percebe-se que amor e perdão carregam consigo forças políticas e a visão de Jesus tem um impacto sobre as atividades humanas. Segundo Arendt, "a perda do respeito nos tempos modernos, ou melhor, a convicção de que só se deve respeito ao que se admira ou se preza, constitui claro sintoma da crescente despersonalização da vida pública e social"43.

\section{À guisa de conclusão}

Perguntamos, no início, pelas contribuições de uma teologia cristã que se entende como pública, fomentando perdão e reconciliação. Procuramos analisar o ambiente que, de momento, naturaliza a violência, pautado, além de outras questões de cunho político, econômico, social e cultural, assim entendemos, por uma noção de justiça retributiva e vingativa. Procuramos, ainda, contrapor a visão de uma justiça transformadora que procura fomentar o perdão e a reconciliação. Entendemos que essas dinâmicas de reconciliação poderiam e deveriam ser meios de estabelecer a ressonância pessoal entre pessoas que são tomadas pela vingança e violência. Através da reconciliação, as vítimas de atos criminosos podem ser "erguidas" (aufgerichtet) e os autores de crimes "corrigidos" (zurechtgebracht). A prisão e o sistema judiciário no Brasil, no entanto, estão voltados para a punição e provocam a brutalização dos autores de crimes. As visões de vida na sociedade brasileira incluem uma mui difundida e reconhecida plausibilidade da violência e da vingança. Essas referências violentas no imaginário coletivo das pessoas podem fomentar homicídios em busca de poder ou de vingança, da autojustiça e dos linchamentos contra supostos ou reais infratores. Já a justiça que está relacionada com a reconciliação e o perdão abre mão de violência e vingança como meio de resolver conflitos.

As igrejas, o poder público e a sociedade civil têm a tarefa de proporcionar condições para que os mecanismos que produzem morte sejam limitados e controlados e que haja espaços seguros nas quais relações humanas possam crescer, possibilitando ressonância e sentimento de autoeficácia. Se há convergências entre a Declaração Universal dos Direitos Humanos e a concepção cristã da dignidade humana, baseada no imago Dei, torna-se tarefa pública das igrejas e da teologia promover a reconciliação, o perdão e a justiça transformadora.

${ }^{41}$ ARENDT, 2008, p. 253.
${ }^{42}$ ARENDT, 2008, p. 251.
${ }^{43}$ ARENDT, 2008, p. 255.

Estudos Teológicos | São Leopoldo | v. 59 | n. 1 | p. 94-107 | jan./jun. 2019 


\section{Referências}

ALMEIDA, Maria da Graça Blaya (Org.). A Violência na Sociedade Contemporânea. Porto Alegre: EDIPUCRS, 2010. Disponível em: <http://ebooks.pucrs.br/edipucrs/ violencia.pdf>. Acesso em: 23 maio 2019.

AMADO, Jorge. Terras do sem fim. São Paulo: Companhia das Letras, 2008.

ARENDT, Hannah. Condição humana. 10. ed. Trad. Roberto Raposo. Rio de Janeiro: Forense Universitária, 2008.

ASSMANN, Jan. Tod und Jenseits im Alten Ägypten. 2. ed. München: Beck, 2010.

CARIELLO, Gabriel; FALDO, Rafael. Exibidas em vídeos, decapitações viram demonstração de força de grupos criminosos. O Globo on-line, 06 de janeiro de 2017, 04:30h, atualizado em 08:36h. Disponível em: <https://oglobo.globo.com/brasil/exibidas-em-videos-decapitacoes-viram-demonstracao-de-forca-de-grupos-criminosos-20735442>. Acesso em: 23 abr. 2019.

CALDEIRA, Teresa P. R. Cidade de muros. Crime, segregação e cidadania em São Paulo. 2. ed. São Paulo: Ed. 34; EDUSP, 2003. Disponível em: <https://csociais.files.wordpress.com/2014/05/ caldeira-teresa-a-cidade-de-muros-completo.pdf $>$. Acesso em: 23 abr. 2019.

CERQUEIRA, Daniel et al. Atlas da Violência 2018. Rio de Janeiro: IPEA; Fórum Brasileiro de Segurança Pública, 2018.

CHESNAIS, Jean-Claude. Violência no Brasil. Causas e recomendações políticas para sua prevenção. Ciência e Saúde Coletiva, v. 4, n. 1, p. 53-69, 1999.

COSTA, Jurandir Freire. A fúria de um mundo agonizante. Folha de S. Paulo, Caderno Mundo, p. A22, 01 abr. 2003. Disponível em: < http://www1.folha.uol.com.br/folha/ mundo/ult94u54275. shtml>. Acesso em: 23 dez. 2016.

COSTA, Sérgio. O Brasil de Sérgio Buarque de Holanda. Revista Sociedade e Estado, v. 29, n. 3, p. 823-839, 2014.

DAMATTA, Roberto. Carnavais, malandros e heróis. Para uma sociologia do dilema brasileiro. 6. ed. Rio de Janeiro: Rocco, 1997.

FREYRE, Gilberto. Casa Grande e Senzala: formação da família brasileira sob o regime da economia patriarcal. 28. ed. Rio de Janeiro: Record, 1992.

HABERMAS, Jürgen. Fé e Saber. In: O Futuro da Natureza Humana. São Paulo: Martins Fontes, 2004. p. 135-154.

HOLANDA, Sérgio Buarque de. Raizes do Brasil. 27. ed. São Paulo, SP: Companhia das Letras, 2015 .

JOAS, Hans. A sacralidade da pessoa. Nova genealogia dos direitos humanos. São Paulo: UNESP, 2013.

KROB, Daniéli Busanello. Violência doméstica contra mulheres e ações de enfrentamento de igrejas: um estudo de caso. 2017. Tese (Doutorado) - Faculdades EST, São Leopoldo, 2017.

KRUG, Etienne G. et al. (Eds.). Relatório Mundial sobre violência e saúde. Genebra: Organização Mundial da Saúde, 2002. p. 5. Disponível em: < https://www.opas.org.br/wp-content/ uploads/2015/09/relatorio-mundial-violencia-saude.pdf>. Acesso em: 23 mar. 2019.

LUTHER, Martin. Kommentar zum Galaterbrief [1519]. München: Siebenstern Taschenbuch, 1968.

MARTINS, José de Souza. Linchamentos: a justiça popular no Brasil. São Paulo: Contexto, 2015. MOLTMANN, Jürgen. Vida, esperança e justiça. Um testemunho teológico para a América Latina. São Bernardo do Campo: Editeo, 2008a.

. „, Sein Name ist Gerechtigkeit“": Neue Beiträge zur christlichen Gotteslehre. Gütersloh:

Gütersloher, 2008b. 
ORGANIZAÇÃO DAS NAÇÕES UNIDAS. Declaração Universal dos Direitos Humanos (1948). Disponível em: <https://www.ohchr.org/EN/UDHR/Documents/UDHR_Translations/ por.pdf>. Acesso em: 23 mar. 2019.

. Taxa de feminicídios no Brasil é quinta maior do mundo: diretrizes nacionais buscam solução. Publicado em 09 abr. 2016 e editado em 12 abr. 2016. Disponível em: <https://nacoesunidas.org/onu-feminicidio-brasil-quinto-maior-mundo-diretrizes-nacionais-buscam-solucao/>. Acesso em: 23 abr. 2019.

PAGNAN, Rogério. Metade do país acha que "bandido bom é bandido morto", aponta pesquisa. Folha de S. Paulo on-line, 05 out. 2015, 02h00. Disponível em: $<$ http://www1.folha.uol.com.br/ cotidiano/2015/10/1690176-metade-do-pais-acha-que-bandido-bom-e-bandido-morto-aponta-pesquisa.shtml>. Acesso em: 23 abr. 2019

ROSA, Hartmut. Resonanz: Eine Soziologie der Weltbeziehung. Berlin: Suhrkamp, 2016.

SCHMITZ, Bertram. Vom Tempelkult zur Eucharistiefeier: Die Transformation eines Zentralsymbols aus religionswissenschaftlicher Sicht. Berlin: LIT, 2006.

SILVA, Luiz Antonio Machado da; LEITE, Márcia Pereira. Violência, crime e polícia: o que os favelados dizem quando falam desses temas? Sociedade e Estado, v. 22, n. 3, p. 545-591, 2007. SINNER, Rudolf von. Cidadania no Brasil: Teoria, prática, teologia. In: BUTTELLI, Felipe Gustavo; LE BRUYNS, Clint; SINNER, Rudolf von (Orgs.). Teologia pública no Brasil e na África do Sul: cidadania, interculturalidade e HIV/AIDS. São Leopoldo: Sinodal; EST, 2014. p. 13-46. (Teologia pública v. 4).

. Teologia pública num estado laico. Ensaios e análises. São Leopoldo: Sinodal; EST, 2018. (Teologia pública v. 7).

SOUZA, Jessé. A Elite do Atraso. São Paulo: Leyva, 2017.

UNITED NATIONS OFFICE ON DRUGS AND CRIME. Global Study on Homicide 2013: Trends, Contexts, Data. Vienna: UNODC, 2013.

VILHENA, Valéria Cristina. Pela Voz das Mulheres: uma análise da violência doméstica entre mulheres evangélicas atendidas no Núcleo de Defesa e Convivência da Mulher-Casa Sofia. 2009. Dissertação (Mestrado) - Pós-Graduação em Ciências da Religião, Faculdade de Humanidades e Direito, Universidade Metodista de São Paulo, São Bernardo do Campo, 2009.

WAISELFISZ, Júlio Jácobo. Mortes Matadas por Armas de Fogo. Mapa da Violência 2015. Brasília: Secretaria Geral da Presidência da República et al., 2015.

ZWEIG, Stefan. Brasil, país do futuro. Trad. Odilon Galotti. Edição eletrônica de Ridendo Castigat Mores. Versão para e-book. eBooksBrasil. Disponível em: <http://www.ebooksbrasil. org/adobeebook/paisdofuturo.pdf>. Acesso em: 23 abr. 2019. 